\begin{tabular}{|c|l|}
\hline Title & Heat shock protein 47 stress responses in Chinese hamster ovary cells exposed to raw and reclaimed wastewater \\
\hline Author(s) & Guizani, Mokhtar; Nogoshi, Y osuke; Ben Fredj, Fahmi; Han, Junkyu; Isoda, Hiroko; Funamizu, Naoyuki \\
\hline Citation & $\begin{array}{l}\text { Journal of Environmental Monitoring, 14(2), 492-498 } \\
\text { https://doi.org/10.1039/c1em10519a }\end{array}$ \\
\hline Issue Date & 2012-02 \\
\hline Doc URL & http://hdl.handle.net/2115/50336 \\
\hline Rights & J. Environ. Monit., 2012, 14, 492-498- Reproduced by permission of The Royal Society of Chemistry (RSC) \\
\hline Type & article (author version) \\
\hline File Information & JEM14_2_492-498.pdf \\
\hline
\end{tabular}

Instructions for use 


\title{
Heat shock protein 47 stress responses in Chinese Hamster Ovary Cells exposed to raw and reclaimed wastewater
}

\author{
Mokhtar Guizani, ${ }^{* a}$ Yosuke Nogoshi, ${ }^{a}$ Fahmi Ben Fredj, ${ }^{b}$ Junkyu Han, ${ }^{b}$ Hiroko Isoda ${ }^{b}$ and Naoyuki \\ Funamizu $^{a}$
}

\author{
5 Received (in $X X X, X X X)$ Xth XXXXXXXXX 20XX, Accepted Xth XXXXXXXXX 20XX \\ DOI: $10.1039 / b 000000 x$
}

\begin{abstract}
As wastewater reclamation and reuse becomes more widespread, risks of exposure to treated wastewater increase. Moreover, an unlimited number of pollutants can be identified in wastewater. Therefore, comprehensive toxicity assessment of treated wastewater is imperative. The objective of this study was to 10 perform a comprehensive toxicity assessment of wastewater treatment systems using stress response bioassays. This powerful tool can comprehensively assess the toxicity of contaminants. In this study, samples from conventional activated sludge treatment, membrane bioreactors (MBRs) with different pore sizes and sludge retention times (SRTs), rapid sand filtration, coagulation, nano-filtration (NF) and reverse osmosis (RO) were investigated. The results of stress response bioassays confirmed that the 15 secondary effluent showed higher stress response than influent indicating that biological treatment generates toxic compounds. The results obtained from molecular weight fractionation of water samples demonstrated that organic matter with a higher molecular weight fraction $(>0.1 \mu \mathrm{m})$ causes toxicity in secondary effluent. Furthermore, supernatant from MBR reactors showed toxicity regardless of SRT. On the other hand, stress response was not detected in MBR permeates except for an MBR equipped with a 20 larger pore size membrane $(0.4 \mu \mathrm{m})$ and with a short SRT (12 days). While rapid sand filtration could not remove the toxic compounds found in secondary effluent, coagulation tests, operated at an appropriate $\mathrm{pH}$, were effective for reducing stress response in the secondary effluent. Experimental findings also showed that stress response was not detected in cases of NF and RO permeate subsequent to MBR treatment.
\end{abstract}

\section{Introduction}

${ }_{25}$ Wastewater reclamation and reuse is gaining widespread acceptance because of increasing water consumption and the scarcity of freshwater resources. Wastewater reclamation and reuse play an important role as an environmentally friendly and cost efficient process in the management of water resources. As 30 early as 1970 , only about 216 million $\mathrm{m}^{3}$ of wastewater was reused in California. However, this increased to 648 million $\mathrm{m}^{3}$ in 2001 [1]. In Europe in the early 1990s municipal water reuse was limited to a few cases, but now more than 200 water reuse projects can be identified [2]. With the popularization of 35 wastewater reclamation and reuse, the risks associated with exposure to treated water increase. In Japan for example, reclaimed wastewater standards cover only a portion of the total water quality index such as E. coli bacteria, turbidity, chromaticity and odour [3]. Therefore a more comprehensive 40 toxicity assessment of reclaimed wastewater is crucial. Since many harmful compounds are contained in wastewater, several methods can be used to assess wastewater toxicity. Bioassay is a powerful and effective tool that can assess the toxicity of harmful matter comprehensively as compared to instrumental analysis [4].

${ }_{45}$ Several researchers have used bioassays to assess water toxicity. Ono et al. [5] evaluated the toxicity of concentrated effluent from a wastewater treatment plant using the Umu test. Farré et al. [6] applied Toxalert and Microtox bioluminescence inhibition assays to assess the toxicity of influent and effluent from several 50 wastewater treatment plants. Jinmiano et al. [7] assessed toxicity of raw wastewater and secondary effluent including several advanced treatment systems such as membrane filtration by bioassay using Oryzias latipes. Kontana et al. [8] evaluated ecotoxicological characteristics of reclaimed wastewater using 55 Vibrio fischeri, Daphnia magna and Tetrahymena thermophilla assays. In addition to these methods, it is also reported that bioassay methods using cultured human cell and mammalian cell lines are effective to assess toxicity on human systems ([9], [10] and [11]). As potable reuse is the trend of today's water 60 management, the aforementioned methods are recommended. In this study, we applied stress response bioassays using Chinese hamster ovary $(\mathrm{CHO})$ cells stably transfected with Heat Shock Protein (HSP) 47 promoter. HSPs are members of a distinctive class of molecules that protect cells against a wide range of 65 injuries. They assist in cellular recovery from stress either by repairing damaged proteins or by removing them to restore protein homeostasis [12]. In this respect, it is known that the stress response system, in particular HSP, functions in all mammalian tissues and cells. Therefore, in bioassay systems 70 utilizing this stress response, it is not necessary to take into 
consideration the basic problems regarding cell specificity [13]. HSP47 molecules are 47-kDa collagen-specific molecular chaperones that are required for molecular maturation of various types of collagens. Unlike most chaperones that recognize several 5 target proteins, collagen is the only substrate protein for HSP47. On the other hand, collagen is the major component of the extracellular matrix and the most abundant protein in mammals, making up $25 \%$ of the total protein to support and maintain cell and tissue structures. It is a main component of cartilage, 10 ligaments, bone and teeth, and is responsible for maintaining the strength and elasticity of many soft tissues, including skin and blood vessels [14].

In previous studies, Narita et al. [15] and [16] performed the 15 basal cyto-toxicity test using cultured human cell lines, NB-1 assay, to samples of water obtained from wastewater and sludge treatment plants. The tests revealed that the toxicity of the effluent was more intensive than the influent and return flows from sludge treatment facilities and the organic matter released 20 from activated sludge bacteria during their decay process contributed to the increase in toxicity in the secondary effluent. Funamizu et al. [17] found that secondary effluent contains some organic matter that causes stress in cells by applying stress response bioassays using $\mathrm{CHO}$ cells transfected with HSP47 25 promoter to samples obtained from a wastewater treatment plant. These studies showed that secondary effluent contains toxic compounds, but toxicity characteristics of secondary effluent are poorly investigated. Investigation of the characteristics of toxicants in secondary effluents is helpful in selecting advanced 30 treatment alternatives. Furthermore, toxicity characterization of samples obtained from MBR as an alternative to activated sludge treatment processes may provide a new standpoint in terms of SRT and solid-liquid separation by membrane filtration. A comparison between the toxicity of MBR sludge and activated 35 sludge was performed by Cicek et al. [18] They reported that overall activity was consistently higher in the MBR, and the biomass in the MBR had a higher viable fraction than the activated sludge. Kimura et al. [19] and Miyoshi et al. [20] reported that accumulation of soluble microbial products (SMP) 40 and dissolved organic matter in the MBRs was significant in the case of shorter SRT. Alfieri et al. suggested that MBR could be operated at higher SRT without drawbacks in terms of biological activity [21]. Moreover, sand filtration and coagulation as typical tertiary treatment processes; along with NF and RO subsequent to 45 $\mathrm{MBR}$ as advanced treatment processes were also investigated.

Furthermore, HSP 47 has proven its effectiveness as a highly sensitive system that can be used for studying the effect of trace contaminants such as heavy metals, organic pollutants and 50 biotoxins. Gupta et al 2010 [22] summarized current development in the application of stress genes and their products HSPs in toxicology. We used in this study the HSP 47. Although evaluating one particular HSP does not provide adequate information on the toxicity of chemicals, this work is a first 55 attempt to investigate the effect of bacterial by-products (e.g.: LPS endotoxin) on water toxicity using bioassays. This research needs to be followed up by other investigation to study the interaction of several compounds and the contribution of each in the context of overall toxicity and synergetic, antagonistic and 60 additive effects that may occur.

The objectives of this study are: 1) to characterize the toxicity of effluent from an activated sludge treatment process by molecular weight distribution and HSP bioassay; 2) to assess the 65 effectiveness of toxicity treatability of pilot-scale MBRs with different SRTs in attenuating water toxicity based on HSP bioassays for MBR permeates and supernatant of mixed liquor in MBRs; and 3) to assess the toxicity treatability of sand filtration, batch-scale coagulation tests, pilot-scale NF and RO as advanced 70 treatment processes.

\section{Materials and methods}

\section{Chemicals and reagents}

The following reagents were purchased from several manufacturers and were used to prepare the culture medium and 75 the required solutions: $\mathrm{NaCl}, \mathrm{KH}_{2} \mathrm{PO}_{4}, \mathrm{KCl}, \mathrm{NaH}_{2} \mathrm{PO}_{4} 2 \mathrm{H}_{2} \mathrm{O}$, bovine serum albumin, $\mathrm{NaN}_{3}$, dimethyl sulfoxide, glycine, $\mathrm{NaOH}$, and sodium dodecyl sulfate (all from Wako), $\mathrm{Na}_{2} \mathrm{HPO}_{4} 7 \mathrm{H}_{2} \mathrm{O}$ (from MP Biomedicals), fetal bovine serum (from Biowest), Geneticin (G418) (from Invitrogen), kanamycin solution, trypsin 80 (ethylenediaminetetra-acetic acid [EDTA]), $\mathrm{MgCl}_{2} 6 \mathrm{H}_{2} \mathrm{O}$, and 4methylumbelliferyl- $\beta$-galactose (MUG) (all from Sigma-Aldrich), and lysis buffer (from Promega).

\section{Samples}

85 As illustrated in Figure 1, wastewater samples were collected from an existing municipal wastewater treatment plant in Sapporo, Japan operated with a conventional activated sludge process and a rapid sand filtration process as advanced treatment. As the overall goal is to promote potable reuse, it is fully understandable 90 that the type of raw water used for the investigation will affect the results. Nevertheless, in this attempt comparison between levels of stress responses before and after treatment process will be interpreted with consideration of the bacterial products. These products are released during biological reaction and their impacts 95 on cells are independent of the type of the water.

Samples were also collected from a pilot-scale treatment process operated in the same plant. It consists of MBRs, fed with the same raw wastewater, that are operated as an alternative to 100 conventional activated sludge systems. The MBR permeate was further treated with a parallel set of nano-filter (NF) and reverse osmosis (RO) membranes. Additionally, a batch scale coagulation test was conducted on secondary effluent. 


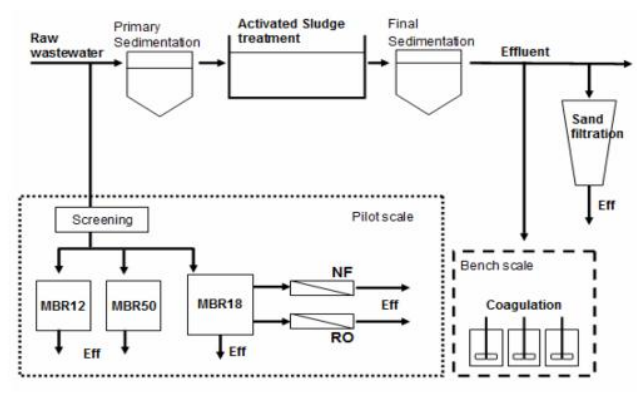

Figure 1: Schematic diagram of wastewater treatment plant and pilotscale treatment system

5

\section{MBR}

Three types of MBRs were operated in parallel in this study. Operational conditions of the pilot-scale MBRs are summarized in Table .1. MBR18 was operated with baffled MBR (BMBR). 10 The BMBR examined in this study was equipped with $6.8 \mathrm{~m}^{2}$ flatsheet-type micro-filtration (MF) membranes (Toray, Tokyo, Japan) and operated at 18 days SRT. The membrane was made of polyvinylidenefluoride (PVDF) and had a nominal pore size of $0.1 \mu \mathrm{m}$. On the other hand, MBR50 and MBR12 are submerged 15 MBRs with SRTs of 50 days and 12 days respectively. Hollowfiber MF membranes (Mitsubishi Rayon Engineering, Tokyo, Japan) made from PVDF polymer were used in MBR50 and MBR12. The nominal pore size of these membranes is $0.4 \mu \mathrm{m}$.

Table-1 Details of three MBRs.

\begin{tabular}{|c|c|c|c|c|c|}
\hline ID & MBR Type & $\begin{array}{c}\text { Volume } \\
\text { (m3) }\end{array}$ & $\begin{array}{c}\text { Membrane } \\
\text { Type }\end{array}$ & $\begin{array}{c}\text { Nominal } \\
\text { Pore } \\
\text { Size } \\
(\mu \mathrm{m})\end{array}$ & $\begin{array}{l}\text { SRT } \\
\text { (day) }\end{array}$ \\
\hline MBR50 & $\begin{array}{c}\text { Submerged } \\
\text { MBR }\end{array}$ & 0.00255 & $\begin{array}{c}\text { Hollow } \\
\text { fiber }\end{array}$ & 0.4 & 50 \\
\hline MBR18 & $\begin{array}{c}\text { Baffled } \\
\text { Submerged } \\
\text { MBR }\end{array}$ & 0.712 & Flat sheet & 0.1 & 18 \\
\hline MBR12 & $\begin{array}{c}\text { Submerged } \\
\text { MBR }\end{array}$ & 0.00255 & $\begin{array}{l}\text { Hollow } \\
\text { fiber }\end{array}$ & 0.4 & 12 \\
\hline
\end{tabular}

\section{NF/RO}

Two 2-inch spiral-wound NF/RO membrane modules were used in this study: NF membrane (LES90, Nitto Denko; Tokyo, Japan) and RO membrane (ES10, Nitto Denko; Tokyo, Japan). 25 Membrane characteristics of the NF/RO membranes are given in Table.2. Membrane flux and recovery, in the continuous operation, were fixed at $460 \mathrm{Lm}^{-2} \mathrm{day}^{-1}$ and $70 \%$ respectively. Permeate samples were collected after one day of operation.
Table-2 Characteristics of NF and RO Membranes

\begin{tabular}{ccccc}
\hline Membrane ID & Material & $\begin{array}{c}\text { Water } \\
\text { permeabilit } \\
\text { y }\end{array}$ & $\begin{array}{c}\text { Zeta } \\
\text { potenti } \\
\text { al } \\
(\mathrm{Lm}-2 \text { day- } \\
1 \mathrm{kPa}-1)\end{array}$ & $\begin{array}{c}\text { Nominal } \\
\text { salt } \\
\text { rejection } \\
(\%)\end{array}$ \\
\hline NF(LES90) & Polyamide & 1.6 & -8.6 & 90.0 \\
RO(ES10) & Polyamide & 1.2 & -15.3 & 95.5 \\
\hline
\end{tabular}

\section{Coagulation}

Secondary effluent from the wastewater treatment plant was used for the batch-scale coagulation test. Coagulation was conducted 35 in $500 \mathrm{~mL}$ glass beakers with the following sequence: 1 minute of rapid mixing at $110 \mathrm{rpm}, 30$ minutes of flocculation at $25 \mathrm{rpm}$, 30-min of settling. In this experiment, polyaluminum chloride (PAC) as coagulant was added at a concentration of $10 \mathrm{mg} \mathrm{Al} / \mathrm{L}$. Several sets of coagulation tests were conducted at different $\mathrm{pH}$ 40 values. The $\mathrm{pH}$ levels in the tests were adjusted using $\mathrm{HCl}(1 \mathrm{~N})$ or $\mathrm{NaOH}(1 \mathrm{~N})$ before adding the PAC. Dissolved organic carbon (DOC) and turbidity were measured after the test.

\section{Molecular weight distribution (MWD)}

45 In order to obtain the information about which molecular fractions cause the toxicity, we applied bioassays to samples at different MWDs. Samples were fractionated into different molecular weights using a series of MF membranes (ADVANTEC, Tokyo, Japan) and ultra filter (UF) membranes 50 (Alfa Laval, Lund, Sweden). Pore sizes of the MF membranes were $0.1 \mu \mathrm{m}$ and $0.2 \mu \mathrm{m}$. The molecular weight cut offs of the UF membranes were $100 \mathrm{kDa}$ and $25 \mathrm{kDa}$. The molecular weight fractionation was carried out on two types of secondary effluent. The first one was fed with only raw wastewater (Case A: samples 55 taken from plant A), while the other one was fed with a mixture of raw wastewater and rejected water from a sludge treatment facility (Case B: samples taken from plant B). Return flow from the sludge treatment facility was mixed into raw wastewater at a rate of $20 \%$. Supernatant of mixed liquor in MBR was 60 fractionated as well.

\section{Toxicity test (HSP assay)}

Chinese hamster ovary $(\mathrm{CHO})$ cells stably transfected with $(+)$ or without (-) a HSP 47 promoter were used for this experiment. It ${ }_{65}$ has already been revealed that the production of stress proteins HSP 47 is induced as a result of the reaction of $\mathrm{CHO}$ cell with a stressor such as wastewater contaminants [13]. The use of mammalian cells such as $\mathrm{CHO}$ cells to assess the stress response pathway related to HSP 47 has high relevance to human health. 70 However, as potable reuse is the target, further investigations on ingestion of contaminated water have to be carried on using cells relevant to digestive tract such as hepG2 or Caco 2 cells. Furthermore, although being with high relevance to human health, using CHO cells to detect only one particular HSP is too limited

75 to be correlated with in vivo tests. This work is a first attempt to study about stress response induced by bacterial by-products and further investigations are needed. 
In this article, heat shock protein 47-promoter-transfected cells will be abbreviated into $\mathrm{HSP}(+)$. The $\mathrm{CHO}$ cells were provided by S. Yokota (Kaneka, Osaka, Japan) and were grown as adherent monolayer in $75-\mathrm{cm}^{2}$ tissue culture flasks using F12 5 Medium (Invitrogen, Carlsbad, CA, U.S.A.), supplemented with $10 \%$ fetal bovine serum, $200 \mu \mathrm{g} / \mathrm{mL}$ of $\mathrm{G} 418$, and $0.1 \mathrm{~g} / \mathrm{L}$ kanamycin solution. The cultures were maintained in a $5 \% \mathrm{CO}_{2}$ incubator at $37{ }^{\circ} \mathrm{C}$. Cell passage was carried out at $80 \%$ confluence at a $1: 2$ ratio using $0.25 \%$ trypsin (1 mM EDTA). 10 HSP47 activity can be determined using HSP47-transformed $\mathrm{CHO}$ cells by incubating the latter with the test samples and measuring the enzymatic activity of $\beta$-galactosidase. When introduced into a chromosome, the HSP47 plasmid can express $\beta$ galactosidase efficiently during stress induction. Experimental ${ }_{15} \mathrm{CHO}$ cells were transformed by inserting the $\beta$-galactosidase gene downstream of the HSP47 promoter while control $\mathrm{CHO}$ cells had the $\beta$-galactosidase gene under the control of the SV40 pA promoter [23]. Isoda et al. [13] developed this system for detecting trace amounts of environmental pollutants and natural 20 toxins and we followed this protocol in this study. Cells were exposed to the sample for three hours and the amount of HSP was measured using a multi-detection micro plate reader in terms of fluorescence (Multi-Detection Micro-plate Reader POWERSCAN HT). In the evaluation, the relative value of HSP 25 production was calculated by the following equation:

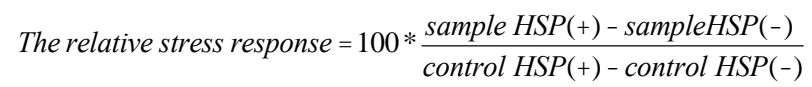

HSP assay is not very accurate and requires a statistical analysis. 30 Student's t test was adopted to statistically assess the differences between the assay results of samples and negative controls. The error bar used in this article represent the 95\% confidence interval, which is wider than standard error bar. This fact must be taken into account when analysing statistical significance. Using 35 standard deviation quantifies variability, but does not consider sample size. Hence, it tells nothing about whether the difference is, or is not statistically significant. It should be noticed that, even when the $95 \%$ confidence intervals overlap, the difference could be statistically significant.

40

\section{RESULTS AND DISCUSSIONS}

\section{HSP assay of raw wastewater, secondary effluent and effluent from sand filtration}

Figure 2 shows the results of HSP assays of raw wastewater, ${ }_{45}$ secondary effluent and effluent from rapid sand filtration. In the figure, the vertical axis shows the relative stress response of each sample compared to the control. Control value is fluorescence from the cells exposed to the medium, which did not contain any samples. When relative stress response exceeds $100 \%$ and it is 50 significantly different from the control $(\mathrm{p}<0.05)$, we define it as toxic to the cell and significance is denoted with asterisks in the figure. The error bar shows the range of observed fluorescence. In the assay, samples were diluted with medium several times to obtain the dose and response relationship such as the low 55 response at low dose range, and the low response at high dose range because of the damage to the cell itself caused by too high a dose.

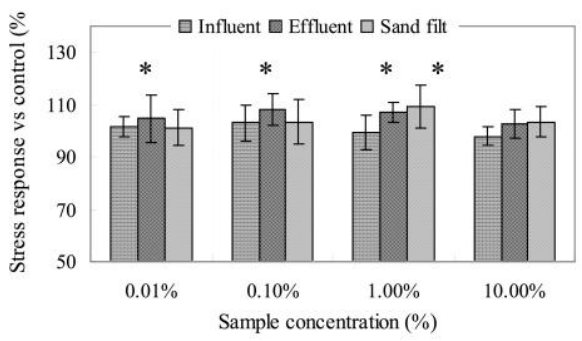

60 Figure 2: HSP assay results of raw wastewater, secondary effluents and effluents from rapid sand filtration. Asterisk in the figure shows the sample with statistically significant difference with control (t-test, $\mathrm{p}<0.05)$.

65 The data in the figure show that the stress response was detected in secondary effluent and effluent from rapid sand filtration; by contrast, raw wastewater showed less stress than that of the influent. This result indicates the possibility that toxic organic matter was generated during the activated sludge treatment 70 process and was not removed by rapid sand filtration. Eckenfelder reported that effluent toxicity might be created in the biological treatment process itself [24]. Rappaport et al., using the Ames test, showed a greater mutagenic response in secondary effluent than that of the influent [25]. Narita et al. have found that 75 the organic matter released from activated sludge bacteria during their decay process contributed to the increase in toxicity in the secondary effluent ([15] and [16]). Guizani et al. studied the endotoxic activity of samples from a wastewater treatment plant. They reported that the ratio of endotoxic material concentration 80 to chemical oxygen demand (COD) of the treated effluent was higher than that of the influent [26].

Heavy metals are hardly removed by conventional wastewater treatment facility (operated using activated sludge process). ${ }_{85}$ According to the annual report of Sapporo sewage works (2009) [30], the investigated treatment plant (raw water) has trace heavy metals below detection limit, except for arsenic and zinc that account for $4 \mu \mathrm{g} / \mathrm{l}$ and $1.6 \mu \mathrm{g} / \mathrm{l}$, respectively. These levels of heavy metals remained constant after treatment. In addition, Guizani 90 and al. 2009 [26] found that the organic matter initially found in wastewater has decreased after treatment. However, HSP response of the effluent was found to be higher that that of the influent. This increase in the stress response is likely to be associated with the release of bacterial by-products (LPS 95 endotoxin) as reported by Guizani et al 2009 [26]. Ben Fredj et al. 2010 [31] reported that, in certain conditions, presence of organic matter (bacterial by-products in this case) masks the heavy metal effect. 


\section{HSP assay of fractionated secondary effluent samples}

Figure 3 illustrates the HSP assay result of two types of fractionated secondary effluent. Figure 3(a) corresponds to samples from plant A (case A) and Figure 3(b) corresponds to 5 samples from Plant B (case B). Both cases showed significant stress response in samples with relatively high MW fractions. By contrast, MW fractions less than $0.1 \mu \mathrm{m}$ did not show significant stress response, therefore, the higher MW fraction $(>0.1 \mu \mathrm{m})$ causes toxicity to cells. Furthermore, the stress response of case B

10 was more intensive than case A. This result agrees with our previous research. Funamizu et al. demonstrated that the rejected water from a sludge treatment plant such as overflow from thickener and rejected water from dewatering processes are some of the origins of the toxicity of effluent from wastewater 15 treatment plants [17]. Guizani et al. also found that high endotoxic activity was confirmed in the rejected waters from sludge treatment facilities [27].

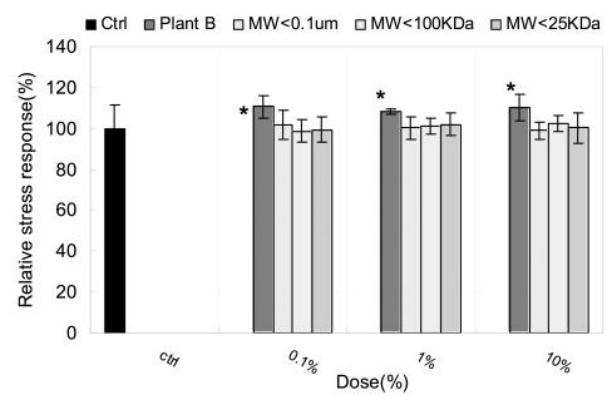

20 Figure 3(a): HSP assay of fractionated secondly effluent; (a) HSP assay results of biologically treated sewage (Case A). Asterisks in the figure show the sample with statistically significant difference with control (ttest, $\mathrm{p}<0.05)$.

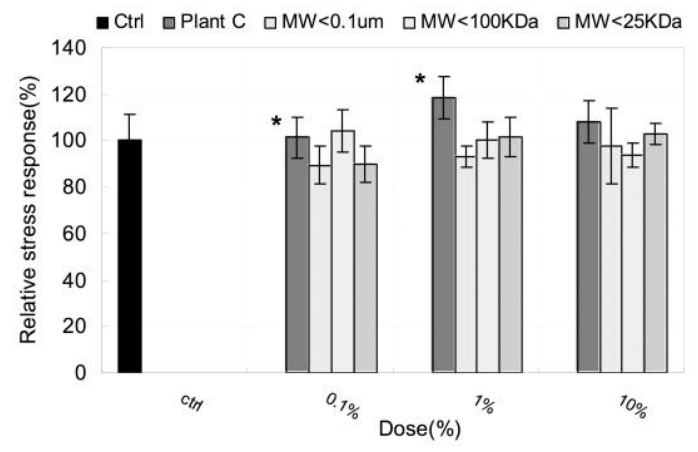

25 Figure 3(b): HSP assay of fractionated secondly effluent; (b) HSP assay results of Biologically treated mixture of sewage and rejected water from sludge treatment facilities (Case B). Asterisks in the figure show the sample with statistically significant difference with control (t-test, $\mathrm{p}<0.05)$.

HSP assay of the effluent from three MBRs and fractionated samples from supernatant from MBR reactors
Because secondary effluent showed toxicity, we focused on the treatment capacity of MBR as an alternative to the activated 35 sludge process. Membranes at longer SRTs are expected to have better biodegradation of organic matter and removal of toxic compounds as compared to the activated sludge process. In this study, three types of MBRs with different SRTs were examined. Figure 4 shows the HSP result of effluent from the three MBRs. ${ }_{40}$ No significant stress response was detected in the MBR permeates except MBR12, which was operated under a shorter SRT (12 days) and equipped with a large pore size $(0.4 \mu \mathrm{m})$. DOC concentration of effluent from MBR12 was also high as shown in Table 3.

Table-3 DOC concentration of influent, effluent and supernatant of activated sludge of three MBRs

\begin{tabular}{lccc}
\hline \multicolumn{1}{c}{ Sample } & \multicolumn{3}{c}{ DOC $(\mathrm{mg} / \mathrm{l})$} \\
\hline & MBR50 & MBR18 & MBR12 \\
\hline Influent & 21 & 21 & 21 \\
Effluent & 4.0 & 3.8 & 4.5 \\
Mixed liquor (supernatant) & & & \\
$<0.45 \mu \mathrm{m}$ & 8.5 & 15 & 15 \\
$0.45-0.2 \mu \mathrm{m}$ & 1.0 & 2.5 & 1.1 \\
$0.2-0.1 \mu \mathrm{m}$ & 1.3 & 0.1 & 2.1 \\
$0.1 \mu \mathrm{m}-100 \mathrm{kDa}$ & 0.7 & 0.6 & 4.9 \\
$100-25 \mathrm{kDa}$ & 1.0 & 2.6 & 1.0 \\
$<25 \mathrm{kDa}$ & 4.5 & 9.3 & 6.3 \\
\hline
\end{tabular}

$$
45
$$

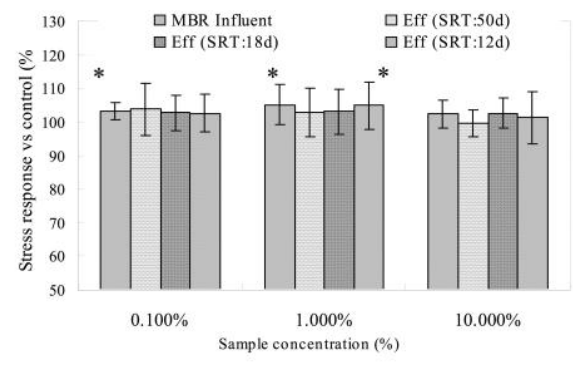

Figure 4: HSP assay of effluent from three MBRs. Asterisks in the figure shows the sample with statistically significant difference with control (ttest, $\mathrm{p}<0.05)$

We also applied HSP assays to the supernatant of mixed liquor of two MBRs with different SRTs (50 days and 12 days) to investigate how SRT affects stress response. Samples were 55 centrifuged and then filtered through a $0.45 \mu \mathrm{m}$ membrane filter.

Figure 5 shows the results of the HSP assays of these samples. The supernatants showed significant stress response, and in both cases, the stress was significant in samples including higher MW fractions $(>0.1 \mu \mathrm{m})$ described in Figure 5(a). As shown in Figure ${ }_{60} \mathbf{5}(\mathbf{b})$, in the 12 days-SRT cases, stress response was significant at all MW ranges. In comparison the DOC concentration $(<0.45 \mu \mathrm{m})$ of MBR12 was higher than MBR50. Holakoo et al. (2006) concluded that longer SRT might lead to the accumulation of higher MW fractions (>100kDa) of biomass-decay-associated ${ }_{65}$ SMP [28]. Using sequencing batch MBR, Bin et al. reported that 
high MW components become more evident at long SRT [29]. MBR operation at shorter SRT induced inadequate biodegradation of toxic organic matter and resulted in toxicity of all MW fractions. Therefore, in the case of MBR12 the MBR 5 permeate showed a stress response because smaller MW fractions carrying toxicants pass through the membrane. The toxic compounds in a supernatant of mixed liquor cannot be removed at longer SRT, but, toxicity was not detected in permeates. This is probably caused by the fact that small molecules aggregated 10 together in larger molecules and were then removed by MBR. Hence, selection of the pore size of the membrane will be important because the size (MW) of organic matter, which has toxicity, is strongly dependent on SRT.

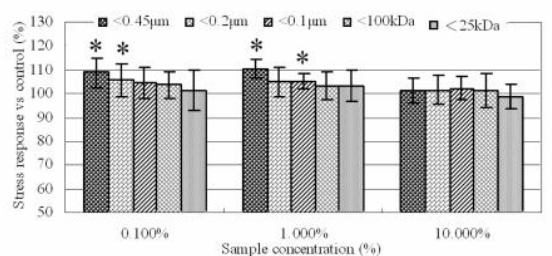

15 Figure 5(a): HSP assay of supernatant of activated sludge of three MBRs; (a) MBR50. Asterisks in the figure show the sample with statistically significant difference with control (t-test, $\mathrm{p}<0.05$ ).

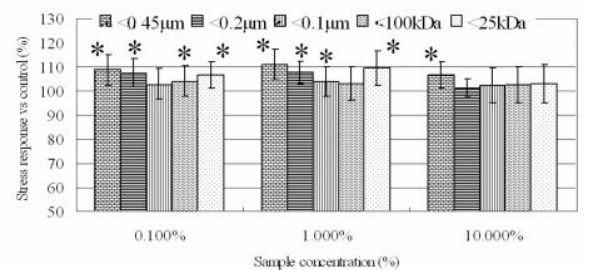

Figure 5(b): HSP assay of supernatant of activated sludge of three MBRs; 20 (b) MBR12. Asterisks in the figure show the sample with statistically significant difference with control (t-test, $\mathrm{p}<0.05)$.

\section{HSP assay of coagulation samples}

In this study, batch scale coagulation tests of secondary effluent were performed using PAC as coagulant at $10 \mathrm{mg}-\mathrm{Al} / \mathrm{L}$ dosages.

25 In these batch tests, $\mathrm{pH}$ was adjusted to several ranges, using $\mathrm{HCl}(1 \mathrm{~N})$ or $\mathrm{NaOH}(1 \mathrm{~N})$ before adding the PAC, to assess the $\mathrm{pH}$ influence on the removal of toxicants and thus on the stress response. Turbidity and DOC removal were described in Figure 6, and as shown in this figure, the best $\mathrm{pH}$ 's for removal of both 30 turbidity and DOC were different. While the best $\mathrm{pH}$ was in range of 6.7-7.1 in terms of turbidity removal, the best $\mathrm{pH}$ for $\mathrm{DOC}$ removal was in a lower range (5.0-5.2). Figure 7 illustrates the results of the HSP 47 assay of samples from coagulation tests at different $\mathrm{pH}$ values. At a $\mathrm{pH}$ ranging from 5.7 to 6.0, 6.7 and 6.9, 35 no stress response was observed. This result indicated that there was no clear relationship between HSP stress response and turbidity or DOC removal. However, $\mathrm{pH}$ levels where no stress response had been observed showed relatively high removal in terms of both indexes. It is thought that higher MW components 40 in the secondary effluent cause toxicity, especially MWs of more than $0.1 \mu \mathrm{m}$, and they can be removed by coagulation with the appropriate $\mathrm{pH}$ adjustment (6 6.7). Indeed, significant stress response was detected only in secondary effluent samples larger than $0.1 \mu \mathrm{m}$ (Figure 3(a) and 3(b)). Appropriate $\mathrm{pH}$ causes the 45 settlement of large molecules and thus no significant stress response was observed in the supernatant.

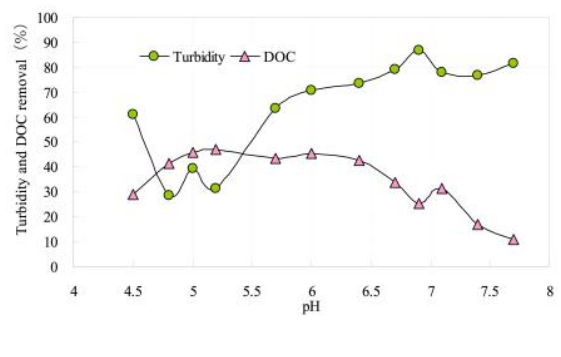

Figure 6: Results of turbidity and DOC removal.

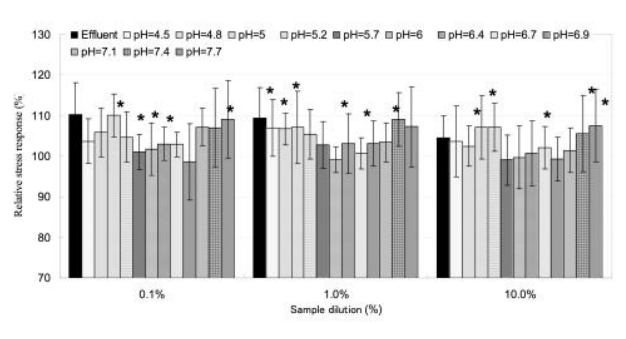

$50 \quad$ Figure 7: HSP assays for coagulation samples. Asterisks in the figure show the sample with statistically significant difference with control (ttest, $\mathrm{p}<0.05)$.

\section{HSP assay of permeate from NF and RO subsequent to MBR18}

${ }_{55}$ Figure 8 shows the result of the HSP assay of permeate from NF and RO subsequent to MBR18. As shown in this Figure, a significant stress response was not detected in any of the samples. Because effluent from MBR18 did not show toxicity, it seems that prior to $\mathrm{NF}$ and $\mathrm{RO}$, toxic compounds were removed by 60 MBR18. The MBR- NF/RO treatment system is effective for the removal of toxic compounds, and this system can be multi-barrier to achieve stable, high quality reclaimed water. However, it remains possible that stress response changes depend on combinations of treatments. Looking ahead, further investigations 65 are needed to study the effect of membrane fouling (due to long term operation) on stress response and release of HSP 47 from $\mathrm{CHO}$ cells exposed to membrane permeates.

Its well known from the literature that $\mathrm{NF}$ and $\mathrm{RO}$ cannot remove 
heavy metals present in their feed water. In addition, these treatment alternatives could reduce significantly the bacterial byproducts. However, no significant stress response was observed in permeates. Thus, the decrease in bacterial by products is 5 associated with no significant stress response, independently of heavy metal presence.

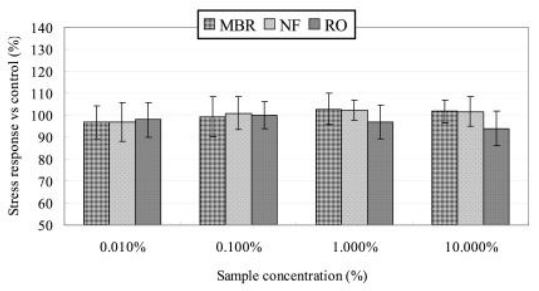

Figure 8: HSP assays for permeate from NF and RO subsequent MBR18

\section{Conclusions}

10 Toxicity assessment using stress response bioassays can be an effective tool for selection of wastewater treatment processes and consideration of the operational conditions of each process. In this study, we applied bioassays using CHO cells with HSP47 promoter to wastewater samples including reclaimed wastewater. 15 The following conclusions were suggested in terms of HSP assays.

The HSP assay could detect the toxicity related to organic matter derived from microorganisms in activated sludge.

Large molecules $(>0.1 \mu \mathrm{m})$ are the main cause of significant stress 20 response.

While rapid sand filtration cannot remove the toxic compounds detected in secondary effluent, coagulation with an appropriate $\mathrm{pH}$ (6 6.7) was effective for reducing stress response.

Stress response can be removed by MBR treatment with the 25 appropriate operational conditions such as SRT and pore size of the membrane. The results obtained from this study suggest that it is better to have longer SRTs and membranes with smaller pore sizes.

No significant stress response is detected in permeates from NF 30 and RO subsequent to MBR treatment, and the MBR-NFRO system can be multi-barrier to achieve stable and high quality reclaimed water.

Although HSP 47 is used to assess the toxicity induced by heavy metals and hydro-soluble organic pollutants, based on this

35 investigation it can be concluded that bacterial by-products contribute significantly to the release of stress response HSP 47.

\section{Notes and references}

The authors acknowledge Wayne E. Porter (Arizona State University-USA), for proof reading of the manuscript and 40 linguistic support.

\section{Notes and references}

${ }^{a}$ Environmental Engineering Department, Graduate school of Engineering, Hokkaido University, Kita 13 jo Nishi 8Chome, Kita-ku,
060-8628, Sapporo, Hokkaido, Japan. Fax: +81 11706 6270; Tel: +81 4511706 6270; E-mail: g_mokh@yahoo.fr(Guizani); gpfdr724@ybb.ne.jp (Nogoshi); funamizu@eng.hokudai.ac.jp (Funamizu).

${ }^{b}$ Graduate School of Life and Environmental Sciences, University of Tsukuba, 1-1-1 Tennodai, 305-8572, Tsukuba city, Ibaraki, Japan. Fax: +81029853 5776; Tel: +81029853 6048; E-mail:

50 fehmibenfredj@gmail.com (Ben Fredj); jhan@sakura.cc.tsukuba.ac.jp

(Han); isoda.hiroko.ga@u.tsukuba.ac.jp (Isoda).

$\dagger$ The first and second authors (Nogoshi Yusuke and Guizani Mokhtar) have equally contributed to this paper.

$\$$ The file "Highlights" summarises the main findings of this paper.

1. Asano, T., Bourton, F. L., Leverenz, H.L., Tsuchihashi, R., Tchobanoglous, G. (2007). Water Reuse- issues: Technologies and Applications, Mc Graw Hill, New York

2. Bixio, D., Melin, T., Thoeye, C., DeKoning, J., Joksimovic, D., Savic, D., Wintgens, T., (2006). Wastewater reuse in Europe. Desalination, 187, 89-101

3. Anonymous, (2005). Manual of Water Quality Standard of Reclaimed Wastewater, Ministry of Land, Infrastructure, Transport and Tourism.

4. Suzuki, M., and Utsumi, H., (1998). Bioassay risk management of water environment. Kodan-sha Scientific, Japan. pp. 3-4 (in Japanese).

5. Ono, Y., Somiya, I., Kawamura, M. and Uenishi, K. (1992). Genotoxicity of organic substances in municipal sewage and its ozonated products. Water Science and Technology. 26(12), 285-291.

6. Farre, M., Garcia, M. J., Tirapu, L., Ginebreda, A., and Barcelo, D., (2000). Wastewater toxicity screening of nonionic surfactants by Toxalert and Microtox bioluminescence inhibition assays. Analytica Chemica Acta 427:181-189.

7. Jinmiao, Z., Zijian, W., (2005). Assessing technological feasibility for wastewater reclamation based on early life stage toxicity of Japanese medaka (Oryzias latipes). Agriculture, Ecosystems and Environment 107, 187-198.

8. Kontana, A., Papadimitriou, C. A., Samaras, P., Zdragas, A., Yiangou, M., (2008). Bioassays and biomarkers for ecotoxicological assessment of reclaimed municipal wastewater. Water Science \& Technology 57, 6 .

9. Kunimoto, M., Yasuhara, A., Sakai, Y., Soma, Y., Nakasugi, O., (1996). Toxicity assessment of the samples from water environment using cultured mammalian cells. Journal of Japan. Society on Water Environment 19(11), 855-860.

10. Fukushima, T., Fujiwara, T., Sugiura, N., Sudo, M., Inoue, T., Hanazato, T., Okubo, T., Kunimoto, M., (2002). Application of simple bioassay using cultured human cell lines to the assessment of total hazards in lake water. Journal of Japan Society of Water Environment 25(2), 119-124.

11. Kfir, R., Prozesky. O. W., (1981). Detection of toxic substances in water by means of a mammalian cell culture technique. Water Research 15, 553-559.

12. Hartl, F.U., (1996). Molecular chaperons in cellular protein folding. Nature 381, 571-579.

13. Isoda, H., Koyama, T., Tasaki, M., Oka, S., Sugiura, N., Maekawa, T., Inamori, Y., Yokota, S., Kitahara, M., Nagata K., (2003). High-sensitive detection of environmental pollutants. US patent and trademark office US006740521B2, Washington, DC, U.S.A.

14. Taguchi, T., Razzaque, M. S., (2007). The collagen-specific molecular chaperon HSP47 : is there a role in fibrosis? Trend in Molecular Medicine 13, 45-53.

15. Narita, H., Funamizu, N., Takakuwa, T., Kunimoto, M., (2005). Role of hydrophilic organic matter on toxicity in decay process of activated sludge. Water Science and Technology 52(8), 63-70.

16. Narita, N., Abe, J., Funamizu, N., Takakuwa, T., Kunimoto, M., (2007). Toxicity assessment of treated wastewater using cultured human cell lines. Environmental Monitoring and Assessment, 129, 71-77. 
17. Funamizu, N., Takenaka, M., Han, J., Isoda, H., (2008). Application of heat shock protein assay and proteome assay to water from wastewater treatment plant. Water Science and Technology. 57.8.

18. Cicek, N., Franco, J.P., Suidan, M.T., Urbain, V., Manem, J., (1999). Characterization and Comparison of a Membrane Bioreactor and a Conventional Activated-Sludge System in the Treatment of Wastewater Containing High-Molecular-Weight Compounds. Water Environment Research 71, 64-70.

19. Kimura, K., Naruse, T., Watanabe Y., (2009). Changes in characteristics of soluble microbial products in membrane bioreactors associated with different solid retention times: Relation to membrane fouling. Water Research 43, 1033-1039.

20. Miyoshi, T., Tsuyuhara, T., Ogyu, R., Kimura, K., Watanabe, Y., (2009). Seasonal variation in membrane fouling in membrane bioreactors (MBRs) treating municipal wastewater. Water Research 43, 5109-5118.

21. Pollice, A., Laera, G., Saturno, D., Giordano. C., (2008). Effects of sludge retention time on the performance of a membrane bioreactor treating municipal sewage. Journal of Membrane Science 317, 65-70.

22. Gupta, S. C., Sharma, A., Mishra, M., Mishra, R. K.,and Chowdhuri, D. K., (2010) Heat shock proteins in toxicology: how close and how far? Life sciences. V. 86 Issue 11-12 pp.377-384.

23. Han, J., Isoda, H., Maekawa, T., (2002). Analysis of the mechanism of the tight-junction permeability increase by capsaicin treatment on the intestinal Caco-2 cells. Cytotechnology 40, 93-98.

24. Eckenfelder, Jr.W.W., (1995). Biological treatability studies: new regulations require a new approach. Environmental Progress. 14(3),172-175.

25. Rappaport, S.M., Richard, M.G., Hollstein, M.C., Talcott, R.E., (1979). Mutagenic activity in organic wastewater concentration. Water Science \& Technology. 13, 957-961.

26. Guizani, M., Dhahbib, M., Funamizu, N., (2009a). Assessment of endotoxin activity in wastewater treatment plants. Journal of Environmental Monitoring. 11, 1421-1427.

27. Guizani, M., Dhahbib, M., Funamizu, N., (2009b). Survey on LPS endotoxin in rejected water from sludge treatment facility. Journal of Environmental Monitoring. 11, 1935-1941.

28. Holakoo, L., Nakhla, G., Ernest K.Y., Amarjeet S.B., (2006). Chelating properties and molecular weight distribution of soluble microbial products from an aerobic membrane bioreactor. Water Research 40, 1531-1538.

29. Dong, B., Jiang, S.,. (2009). Characteristics and behaviors of soluble microbial products in sequencing batch membrane bioreactors at various sludge retention times. Desalination 243, 240-250.

50

30. Anonymous, (2009). Annual report of Sapporo sewage works, Japan.

31. Ben Fredj, F., Irie, M., Han, J., Yamada, P., Limam, A., Ghrabi, A., Morio, T., and Isoda, H. (2010). Stress response of heavy metal mixture present in wastewater and leachate on heat-shock protein 47-transfected cells. Environmental Toxicology and chemistry. Vol 27 N 7 pp. 1637-1647. 